\title{
Las formalidades ad luciditatem y ad regularitatem en el contrato de franquicia en Colombia ${ }^{1}$
}

\section{The formalities ad luciditatem and ad regularitatem in the franchise agreement in Colombia}

Recibido: 02 de marzo de 2015 - Revisado: 11 de noviembre de 2015 - Aceptado: 08 de abril de 2016.

Eduardo Salgado Figueroa ${ }^{2}$

\section{Resumen}

El presente estudio pretende analizar cómo el control contractual emanado del contrato de franquicia se relaciona con algunas formalidades, las cuales se imponen como norma de orden público para el claro beneficio del consumidor y el franquiciado. Para tal efecto se presenta una noción del control como se manifiesta en la normativa colombiana. Se describe cuándo se controla la gestión administrativa en una sociedad y se plantea qué es el control natural en la franquicia. Todo lo anterior se dirige a resaltar la importancia de las formalidades ad luciditatem y ad regularitatem para luego demostrar que su inobservancia perjudicará a ciertos sujetos que aparecen en la cadena de franquicias.

Palabras clave

Franquicia, control, formalidad.

\begin{abstract}
The present study aims to analyze how the contractual control emanated from the franchise agreement is related to some formalities, which are imposed as a rule of public order for the clear benefit of the consumer and the franchisee. For this purpose a notion of control is presented as manifested in Colombian regulations. It describes when the administrative management in a company is controlled and what is the natural control in the franchise is considered. All of the above is aimed at highlighting the importance of the formalities ad luciditatem and ad regularitatem and in order to demonstrate that their non-compliance will harm certain individuals who appear in the chain of franchises.
\end{abstract}

Keywords

Franchise, control, formality.

\footnotetext{
Artículo de Reflexión vinculado al proyecto de investigación "Nuevas tendencias del régimen contractual en el derecho comercial y de consumo en Colombia" vinculado al grupo de investigación en Justicia Global de la Universidad Tecnológica de Bolívar, Cartagena, Colombia.

2 Magíster en Derecho de la Universidad Sergio Arboleda, Bogotá, Colombia. Abogado y especialista en Derecho Comercial de la Universidad Libre, Cartagena, Colombia. Profesor de tiempo completo en el programa de Derecho de la Universidad Tecnológica de Bolívar, Cartagena, Colombia. Correo electrónico: esalgado@unitecnologica.edu.co

Para citar este artículo use: Salgado, E. (2016). Las formalidades ad luciditatem y ad regularitatem en el contrato de franquicia en Colombia. Civilizar Ciencias Sociales y Humanas, 16(31), 49-66.
} 


\section{Introducción}

El franquiciante al celebrar contratos de franquicia le asiste una obligación: hacer conocer a los consumidores que él es el sujeto creador de la cadena de comercialización. Frente al franquiciado, la obligación consiste en hacer conocible que él es el sujeto creador de la cadena para efectos de hacer efectivo el contrato y cumplir algunas disposiciones en materia de responsabilidad de manera más expedita. El no cumplimiento de estos sencillos deberes genera una problemática para las partes débiles del contrato de franquicia. En virtud de dar una explicación del porqué se originan estas obligaciones, se analizan las formalidades ad luciditatem y ad regularitatem en relación con el control contractual.

La reflexión se encamina a elucidar la importancia de las formalidades ad luciditatem y ad regularitatem para evidenciar la necesidad de una mejor oponibilidad, efectividad y utilidad en el contrato de franquicia. Se demostrará porqué la franquicia es un negocio esencialmente controlado y para ello, se estudiará lo que se entiende por red de distribución para desembocar en la red particular de franquicias.

Sumado a lo anterior, se estudia la forma del contrato así como las formalidades ad luciditatem y ad regularitatem, de modo que contribuyan a la comprensión sobre la relevancia del cumplimiento de la obligación del franquiciante para determinar sus efectos positivos. Se concluye que la norma sobre la inscripción de control establecida en el artículo 30 de la ley 222 de 1995, debe aplicarse a los franquiciantes como respuesta a que la franquicia es un negocio controlado y a que en relación con las formalidades referidas, los efectos de tal registro apuntan a un derecho tuitivo para el franquiciado y para el consumidor.

El presente artículo se estructura de la siguiente manera: se hace una descripción sobre el control establecido en la norma colombiana. Se sintetiza en aras de su comprensión, el concepto de contrato de franquicia, su control natural, y al mismo tiempo se presenta una visión desde la óptica de la relación de consumo. A continuación, se resalta la importancia de la red de distribución con miras a llegar a la red de franquicia. Se analizan y explican a través del método hermenéutico las formalidades ad luciditatem y ad regularitatem para luego entenderlas como obligación del franquiciante. Por último se presentan las conclusiones.

\section{Visión del control o subordinación en la norma colombiana}

\section{Presunciones de control o subordi- nación.}

El control o subordinación lo regula la ley 222 de 1995 dentro de los preceptos fijados para la figura del grupo empresarial. Su reglamentación determina el deber de inscripción en el registro de la cámara de comercio, por parte de la persona jurídica o natural que lo ejerza, so pena de incurrir en sanciones y responsabilidades.

La subordinación, descrita por la legislación colombiana, es una serie de presunciones de hecho por parte de la ley. Enunciaciones que implican un esfuerzo de la controlante para desvirtuar la asunción de control que se le puede atribuir, y para ello, puede acudir a cualquier medio probatorio pertinente.

El concepto abstracto del control societario que se acaba de mencionar se sustenta en el artículo 27 de la ley 222 de 1995, el cual instaura las denominadas "presunciones de subordinación". Se trata de tres supuestos fácticos que permiten, en la práctica, determinar con criterios relativamente objetivos, cuándo se considera que la autonomía de decisión de una empresa se supedita a dominio de otra u otras personas. Dichos supuestos están definidos según el esquema de presunciones (Reyes-Villamizar, 2006).

La ley 222 de 1995 se refiere al control abstracto al tratar tres presunciones -no defi- 
nitivas - específicamente: a) tener la matriz el $50 \%$ del capital directa o indirectamente; b) tener la mayoría decisoria mínima en la junta de socios o en la asamblea general de accionistas, o tener la mayoría decisoria para elegir la junta directiva; y c) cuando directamente o por concurso con alguna subordinada en razón de un negocio o acto la controlada o sus socios, o alguno de ellos, estén dominados por la controlante en las decisiones que se tomen en el órgano de administración de la sociedad. Esta última causal es la que interesa a este estudio y se denomina control contractual.

Valga decir en este punto que los órganos de administración de las sociedades son las juntas directivas, representantes legales, liquidadores, factores, etc.; así mismo la Superintendencia de Sociedades (2007) expresó que los administradores son los que tienen la facultad de contratar en nombre de la sociedad, cuando aquella ha sido otorgada en el contrato social (ley 222 de 1995, art. 22).

De todo esto se colige que la subordinación es sumamente importante, de ahí que se erija como presunción para la conformación del grupo empresarial y porque participa en el funcionamiento de negocios jurídicos como la franquicia, tal como se verá más adelante. Así el Consejo de Estado sostiene en sentencia 16 de octubre de 2014 que las normas distinguen entre "situación de control", entendida como simple subordinación entre dos o más entidades, y "grupo empresarial", figura que implica tanto subordinación como unidad de propósito y dirección. Pese a ello, ambos conceptos comparten una particularidad: su configuración no está sujeta a declaración por parte de autoridad alguna, sino a la simple ocurrencia de los supuestos de hecho determinados por la ley.

Ramírez (2001) expresa que el control es el poder de determinar la gestión administrativa de otra sociedad, es decir, la clara manifestación de detentar el dominio sobre una persona jurídica independiente, desde las formas establecidas positivamente tal como el control externo.

\section{El control contractual sobre la ges- tión administrativa de una sociedad.}

La administración en las sociedades es la que implica una gestión sobre el patrimonio de la sociedad comprendida en fases que van desde lo económico hasta lo jurídico, como cuando se ejerce la función de contratar o se asumen deberes jurídicos para dar cumplimiento al objeto social.

Los administradores son los que someten la actividad empresarial a políticas económicas y ejercen contratos en virtud del objeto social de las sociedades, y es a esto a lo que se le llama gestión de la función administrativa de la sociedad, pues la dirección le pertenece, como bien se sabe, a la junta de socios o a la asamblea general de accionistas.

La gestión administrativa en su ámbito económico patrimonial engloba ciertas etapas de organización, dirección, ejecución y control. En el desarrollo de estos escalafones se celebran actos jurídicos de variada índole, presenciando de esta manera, la gestión administrativa en su fase jurídica. Al respecto, Ramírez (2001) es claro en decir que:

El contenido de la actividad de gestión o actividad administrativa es económico-patrimonial $\mathrm{y}$ de naturaleza funcional, ya que gracias a esta se lleva a cabo la finalidad de la sociedad. La administración recae sobre un patrimonio y es imprescindible para la consecución del objeto social de la sociedad; por tanto se incluye dentro de esta a todos los actos que sean necesarios para la realización del mismo. Bajo esta finalidad se enmarcan diferentes clases de actos no solo de conservación del patrimonio sino también de disposición o de asunción de obligaciones exceptuando aquellos incluidos en la competencia de la Junta General. En primer lugar, es en esta variedad de actuación, consecuencia de la competencia general en materia de gestión y la finalidad a la que se orienta en donde en principio consideramos que se asienta el poder que posee el órgano administrativo sobre el destino económico de la sociedad (pp. 645-646). 
En aras de conservar el patrimonio y poner en funcionamiento el objeto social, acometer actos jurídicos es clara expresión del ejercicio de la gestión administrativa. Asumir obligaciones también forma parte de ese ejercicio, del cual empresas o sociedades permiten que otros empresarios asuman el control sobre la gestión en la administración, y en el desarrollo del ejercicio de esa gestión, convergen responsabilidades sobre la sociedad controlada. Esta es la expresión del control contractual externo.

Sobre el control contractual externo se puede decir que se presenta en distintas circunstancias, tal como cuando procede de personas que ayudan a superar crisis financieras o incluso el que proviene de actos exógenos como los contratos de colaboración mercantil; en este sentido Embid (citado por Ramírez, 2001) afirma:

Si entendemos el control externo como la posibilidad de acceder al Órgano de Administración sin antes poseer la mayoría de los derechos de voto en la Junta General, se pueden identificar efectivamente determinados supuestos en los que no necesariamente preexiste un vínculo financiero, p. e. el nombramiento de un manager especializado y necesitado por la sociedad para superar una crisis económica, nombramiento de un acreedor como administrador a fin de evitar una declaración de quiebra o para desvincularse del control no interno de otra sociedad (ibídem), la celebración de determinados contratos de colaboración (p. 660).

Antes de entrar en otras consideraciones, y sin ánimo de que el concepto sea definitivo, se sugiere una definición de control externo por vía de negocio jurídico, así: es el poder de dominio que ejerce una persona natural o jurídica aun sin carácter societario, sobre la gestión administrativa de una sociedad a razón de un negocio jurídico de colaboración mercantil y, por consiguiente, podrá ser influyente en las decisiones que atañen al patrimonio de la sociedad.
Lo expuesto ubica a la franquicia como uno de los contratos de colaboración que genera el control contractual de que habla la ley 222 de 1995, y es por ello que se hace necesario explicar a qué tipo de franquicia se quiere hacer referencia, también entender su control natural y la función que cumple la red de franquicia.

\section{La franquicia: sobre su control natural y la red de franquicias}

\section{La franquicia.}

Por el contrato de franquicia podemos apreciar una apariencia unificada y un comportamiento comercial coordinado, con lo cual se pretende la copia de un éxito organizacional probado en el ámbito de empresa, que requiere para llegar a tal punto, una larga sucesión de tiempo que haga constar su calidad, así como también se involucran dentro de su marco contractual una serie de contratos como el know how, licencia de nombre y marcas y asistencia técnica continua, sin los que no podría el franquiciador asegurarse de la réplica que el consumidor conoce de su negocio.

La franquicia más conocida es sin duda alguna la business format franchise (franquicia empresarial), la cual contiene varios elementos esenciales para causar su existencia jurídica: know how, control, licencia de nombre y signos distintivos, además de la práctica de asistencia técnica.

Se denomina franquicia comercial o empresarial al sistema de reproducción de un modelo de negocio apto para generar rentabilidad a través de la comercialización de productos y/o servicios, que combina la autorización de uso de nombre comercial, marcas y otros derechos de propiedad industrial, incluyendo conocimientos específicos, estén o no patentados, cuya titularidad, usufructo y/o derecho de utilización y transmisión a terceros asiste a una de las partes, denominada "franquiciante" o "franquiciador", con la prestación por esta de servicios de asistencia técnica y comercial 
constante a la otra parte, denominada "franquiciado" o "franquiciatario", quien actuará por su propia cuenta y riesgo, obligándose a ejecutar acciones $\mathrm{y} / \mathrm{o}$ prestaciones, por las que aquella obtiene un beneficio económico (Bliman, 2006, p. 172).

Este contrato es de los llamados atípicos, encuadrándolo como indica Camacho (2005) en la categoría de los que tienen tipicidad social sin regulación, siendo relevante su planteamiento dentro del comercio, sin poder desconocer su poderío en los mercados del mundo. Tal modelo es de gran usanza para alcanzar al consumidor convirtiéndose también en un contrato de colaboración empresarial, destinado por el productor y cumplido con cierta independencia jurídica, por el franquiciado. También podría decirse que sirve como canal de comercialización para el dueño de la red de franquiciantes.

La empresa productora (así como la mayorista) puede llegar al público consumidor (o a los minoristas) por medio de canales propios o de canales integrados por terceros. En el primer caso, el productor asume el riesgo de la venta directa, así se trate de ventas realizadas exclusivamente a mayoristas. En el segundo caso, el canal está constituido por comerciantes que actúan en nombre propio, unidos por contratos uniformes a la empresa productora que, de este modo, se apoya en centros autónomos que pueden adoptar figuras más o menos rígidas (Farina, 2005, p. 454).

Hay diversidad de definiciones de este contrato, como la que nos ofrece el Instituto Internacional para la Unificación del Derecho Privado que en septiembre de 2002 aprobó la ley modelo de franquicia o model franchise disclosure law, la cual entiende franquicia como:

Conjunto de derechos cedidos por una parte el franquiciador autorizando y requiriendo a la otra parte [el franquiciado], a cambio de una compensación económica directa o indirecta, el compromiso de vender bienes o servicios de la franquicia, para su propio beneficio y conforme al sistema diseñado por el franquiciador, el cual incluye saber-hacer, asistencia técnica, los procesos sustanciales relativos a la operación y control de la franquicia y el uso de los derechos de propiedad intelectual vinculados con la misma (Peres, 2003, p. 211).

De manera análoga se presenta la definición hecha por el reglamento 4087 de $1988 \mathrm{de}$ la Comunidad Económica Europea:

Un conjunto de derechos de propiedad industrial o intelectual relativos a marcas, nombres comerciales, rótulos de establecimiento, modelos de utilidad, diseños, derechos de autor, know-how o patentes, que deberán explotarse para la reventa de productos o la prestación de servicios a los usuarios finales (art. 1.3).

De lo anterior se puede concluir que la franquicia es un negocio de colaboración empresarial implementado para la reiteración o copia de un proceso de comercialización empresarial probado y con éxito, cuyo sistema debe comprender un formato de prestaciones tales como la licencia de uso de marca o nombre comercial para los productos y servicios; transferencia tecnológica de know how y demás procesos que conlleven la protección del goodwill ganado, y como contraprestación, se dará un derecho de reventa que resultará en un margen de ganancia.

De este contrato deviene un pago de regalías mensual sobre la reventa. También se desembolsa un importe de entrada a la red de franquicias, y una mensualidad por la utilización de la marca o demás derechos intelectuales otorgados para el cumplimiento de la obligación de mantener el negocio por parte del franquiciado. Es por todo ello que la franquicia de servicios requiere como obligación permanente del franquiciante conceder asistencia técnica al franquiciado: cursos sobre la producción y puesta a punto de los productos a vender, además de los referentes a mantener, el know how $\mathrm{y}$ los secretos empresariales. Todas estas prestaciones son vitales a la hora de poner a funcionar 
la empresa, so pena de dar por terminado fulminantemente el contrato, por incumplimiento de obligaciones.

Más allá de que haya categorías de franquicias como las distingue Simon (2007) como las de product franchising y business format franchising, en este documento se alude a la franquicia conocida como business format franchising. Este tipo de franquicia es regularmente conocido por su uso, según el cual el franquiciante lo que quiere es enseñar métodos y procesos para la protección de su producto y marca, además de asegurar la llegada del mismo al consumidor final.

\section{La colaboración en la franquicia.}

Es conveniente hacer algunas precisiones sobre la característica de la colaboración en el contrato de franquicia. Lo primero que hay que resaltar es el tema de la independencia del franquiciado que emana como resultado de la franquicia tipo business format. Algunos autores como Simón (2007, p. 200) y Marzorati (2008, pp. 229-230) comparten lo de la independencia económica e incluso técnica del franquiciado, como también la independencia jurídica. Otros como Martorell (1993) y Navas y Mosquera (2009) podrían encuadrarlo en un contrato colaborativo pero no independiente, puesto que el control tiene la función de integrarlos de tal manera que las marcas y el funcionamiento de la red del franquiciante no se vea comprometida.

Sería un error concluir que por ser un contrato colaborativo se debe excluir el control como obligación principal, pues analizadas así las cosas devendría en una inexistencia jurídica del contrato. El franquiciante en cumplimiento de la obligación contractual de control debe asistir paso a paso al franquiciado, a fin de que el prístino funcionamiento de la copia sea tan efectivo como el de la empresa original. Es así que se afirma que la colaboración va ligada al control.

Sin embargo, ajena al control se encuentra la independencia técnica y jurídica que se denota en ciertos aspectos como los tributarios, laborales, etc., a cargo del franquiciado, los cuales no tienen la capacidad de afectar al franquiciante; caso distinto sucede si el acto se presenta según los alcances de la relación de consumo establecida en las normas de la ley 1480 de 2011, de ahí radica la relevancia de ciertas formalidades.

\section{El control natural de la franquicia.}

El control en la franquicia es un elemento natural del contrato y esto lo determina no el derecho positivo, dado el carácter atípico del contrato en mención, sino la posición unánime de la doctrina al expresar que es inmanente de este tipo de figuras para lograr el propósito del franquiciador.

En cuanto al sometimiento que conlleva este negocio jurídico, en los casos de franquicia el que otorga el derecho a utilización de marca, ofrece sus métodos de comercialización y demás técnicas para la producción y posterior promoción para la reventa del producto. Solo quiere salvaguardar su prestigio empresarial. De ahí radica el control que del propio contrato surge.

Es así como expresamos que para este contrato la red de comercialización es integrada casi en su totalidad, pues el control ejercido así lo demarca y dada la rigidez de la red de franquicia, el franquiciado debe seguir forzosamente lo determinado por el productor en ciertos aspectos. Se puede decir que la subordinación tiende a ser más económica que jurídica.

En cuanto a la autonomía como punto de vista que se relaciona con el control natural, algunos autores adoptan una postura clara como Marzorati (2008, p. 231) al manifestar que el franquiciado mantiene su independencia económica y jurídica, toda vez que los costos de la empresa, su organización interna, contratos laborales, impuestos a pagar, y demás obliga- 
ciones de cualquier comerciante, tales como la renovación de la matrícula mercantil, pagos de arrendamiento de local comercial, e inclusive la financiación para la ejecución del contrato de franquicia, los asume el franquiciado.

A su turno, autores como Holand (citado por Izuzquiza, 2008) exponen la estrechez que causa el control en el contrato referido y reafirman la autonomía de las empresas, así:

Arranquemos con una verdad objetiva: el contrato de franquicia involucra control [...] Objetivamente considerado, el franchising se enrola en dicha posición, habida cuenta de que, a partir de la suscripción de un contrato entre entes perfectamente independientes entre sí, una parte impone a la otra una dominación técnica, la implementación de un sistema de comercialización (y no otro) de un producto (y no otro), la obligatoriedad de asumir diversos sistemas contables especiales, auditorías, revisiones paulatinas, carga de apoyarse en determinadas instituciones bancarias, financieras, de seguros (y no otras), la utilización de un determinado tipo de locales, ropaje para el personal, criterios de selección y adoctrinamiento del mismo, política de ventas, publicidad, precios, etc. (pp. 19-20).

Ahora bien, enunciar que una red es rígida o integrada, se hace porque atiende a un control extremo, así, de la lista de derechos que pueden consignarse en un contrato de franquicia, a favor del franquiciador, se destaca el de "ejercer el control y auditoría permanente de la operación que realiza el franquiciado" (Navas \& Mosquera, 2009, p. 294). En el mismo sentido Echebarría (1995) sostiene:

En la FTC Interpretative Guidelines 1.A.1.b [se] habla sobre un "control significativo" haciendo referencia al grado de dependencia económica del franquiciado de la mayor experiencia y capacidad del franquiciador, experiencia y medios, a los que se accede por medio del contrato. Con la imposición del método operativo del franquiciado se pretende conseguir una reducción de riesgos empresariales, y el correlativo aumento de las posibilidades de éxito comercial. Los controles tipificados en este sentido, son los relativos al establecimiento de nuevos negocios, implantación en locales o áreas de negocio, el diseño y apariencia del local, fijación de horarios comerciales, utilización de técnicas de producción o comercialización, las prácticas y sistemas contables, la política de personal, las campañas promocionales y sus cargas financieras, el libre acceso a la clientela, etc. (p. 28).

En el mismo sentido se puede decir que la Cámara de Comercio de Bogotá ha certificado como costumbre mercantil para el contrato de franquicia que el franquiciador haga auditoría permanente sobre el negocio del franquiciado. También es costumbre mercantil certificada que en el contrato de franquicia, el franquiciador entregue al franquiciado un manual de operaciones y procedimientos, con la finalidad de que este último pueda realizar exitosamente el negocio contratado ${ }^{1}$.

Todo lo anterior da cuenta de un control propio perteneciente al contrato de franquicia, del que puede servirse el franquiciador para establecer cierta gestión al franquiciado, como por ejemplo el tema de auditorías y el manual de operaciones precitados.

\section{El control de la franquicia desde la óptica de la relación de consumo.}

Como es sabido, la relación de consumo ha sido construida jurisprudencialmente en Colombia a partir del antiguo Estatuto del Consumidor (Decreto 3466 de 1982). Entre otros pronunciamientos de la Corte Suprema de Justicia destacamos la del magistrado Pedro Munar Cadena:

[...] la relación de consumo constituye una particular categoría que surge entre quienes se dedican profesionalmente a elaborar o proveer bienes o prestar servicios con quien los adquiere con el fin de consumirlos; y es precisamente el consumidor, quien, por encontrarse en condiciones de vulnerabilidad económica y de desequilibrio, es destinatario de una 
especial protección normativa; por supuesto que la profesionalidad del productor, que lo hace experto en las materias técnicas y científicas en torno de las cuales realiza su labor, su sólida capacidad económica, su vocación para contratar masivamente, las modalidades de contratación a las que acude, entre muchas otras peculiaridades, lo sitúan en un plano de innegable ventaja negocial que reclama la intervención de legisladores y jueces con miras a restablecer el equilibrio perdido (Sentencia del 30 de abril de 2011).

Con esto se quiere determinar que la relación de consumo y su consecuente responsabilidad de mercado, fijada especialmente para los productores, es una referencia indirecta en materia de control ejercido por parte de cualquier productor por medio de una red de comercialización. Vale la pena resaltar que el vínculo de consumo crea una responsabilidad que desvirtúa la independencia jurídica que tanto se pregona en los contratos de colaboración empresarial.

Para ilustrar mejor la relación entre el control a través de una red de franquicia y la responsabilidad de mercado, Martorell (1993, p. 553) enseña que si el franquiciante resulta beneficiado por los cánones o royalties cobrados al franquiciado, no sería injusto responder por los daños causados a terceros producto de la actividad empresarial de la Franquicia.

Como corolario de lo anterior, es lógico que observemos cómo la responsabilidad de mercado está positivizada en Colombia desde la expedición de la ley 1480 de 2011, todo según la doctrina del vínculo de consumo que legítima al consumidor a perseguir indistintamente y de manera solidaria al proveedor o al fabricante del producto.

Quizá la afrenta que representa esta responsabilidad a la independencia a que están sujetas las partes en los contratos de colaboración, es decir, entre el principal de la red (productor o fabricante) y el colaborador (franquiciado, dis- tribuidor, concesionario) es un indicio de que el llamado control contractual se refleja en toda la red de franquicia. Lo anterior puede tomarse como un punto para explicar el por qué se legitima al consumidor a perseguir al franquiciante en modalidad de proveedor o productor, si con estos el consumidor no ha contratado. También se hace entendible, por el mismo motivo, la legitimación del consumidor para accionar contra aquellos, por ejemplo, en materia de garantías, más allá de lo elaborado para lo del riesgo en el ejercicio de una actividad de la cual aparece una responsabilidad objetiva.

Además de lo dispuesto en nuestra Constitución Política (art. 78) y lo reiterado por la jurisprudencia sobre la determinación de la responsabilidad de mercado (Sentencia C-1141 de 2000), hay formalidades que permiten establecer claramente si el consumidor acude a la responsabilidad derivada de la relación de consumo o a la responsabilidad objetiva según el régimen del riesgo por la actividad ejercida. Por lo tanto, se hace necesario su estudio con miras a relacionar sus incidencias con el control de la franquicia y con la responsabilidad de mercado.

En este contexto, la muestra de existencia contractual de una red de franquicia de cara a determinar el tipo de responsabilidad a la que quiera acudir el consumidor, es una función atribuible a una formalidad. A modo introductorio las formalidades pueden presentar varias funciones, a saber: informar o hacer oponible la situación de control del franquiciante; determinar las situaciones en que el franquiciado puede repetir eventualmente en contra del franquiciante; intervención del Estado como protección a la parte débil de la contratación y, la aparición al mundo jurídico de la red de comercialización. Esto hace menester, que previo a la explicación de las formalidades, se plantee una breve noción de qué es una red de distribución en términos jurídicos, ya que su eclosión esclarece el papel del franquiciante y su responsabilidad ante el franquiciado y ante el consumidor. 


\section{Noción sobre la red de distribución.}

La red de distribución es un instrumento que nace de la voluntad del empresario para la reventa (distribución), expansión, mantenimiento (agencia) y control de goodwill y marcas (concesión y franquicia). Desde la red se verterán instrucciones atadas al negocio jurídico correspondiente al canal que se acogerá para la circulación del producto o servicio. Es conformada por la reunión de diferentes modalidades contractuales (Valenzuela, citado por Fontcuberta 2009, p. 107), que se conocen como canales de comercialización, los cuales tienen la capacidad de organizar una colaboración vertical u horizontal de empresas emanada por órdenes otorgadas por el fabricante, productor, franquiciante o concedente, y que en suma, su finalidad común es la de llegar al consumidor final, trayendo beneficios a la marca del producto e implementando una exclusividad bien sea de productos o de territorio.

La red como decisión negocial del empresario determina la aparición de los contratos de colaboración mercantil. No importa el número general de colaboradores o intermediadores que se manifiesten, pues en últimas, esto depende de la voluntad del empresario creador de la red. Ello explica que más allá de que los contratos de colaboración mercantil sean bilaterales en cuanto a su formación, la red nace en tanto exista un contrato de colaboración. Para más claridad, en materia de causa contractual la red es el motivo que induce a contratar al fabricante o productor.

La comprensión de este punto debe ser sencilla cuando se entiende que el empresario dueño del producto puede actuar por su propia cuenta, es decir, según su propio andamiaje empresarial, al crear sucursales o agencias que le ayuden con sus planes estratégicos de mercado. Existe, sin embargo, una segunda alternativa para ingresar a un mercado, que es la actuación en nombre propio por otro empresario, pero controlado en menor o mayor medida por un productor. De esto se trata la colaboración en red a través de canales. En este sentido Farina (2005) expresa:

La empresa productora (así como la mayorista) puede llegar al público consumidor (o a los minoristas) por medio de canales propios o de canales integrados por terceros. En el primer caso, el productor asume el riesgo de la venta directa, así se trate de ventas realizadas exclusivamente a mayoristas. En el segundo caso, el canal está constituido por comerciantes que actúan en nombre propio, unidos por contratos uniformes a la empresa productora que, de este modo, se apoya en centros autónomos que pueden adoptar figuras más o menos rígidas (p. 454).

Para ampliar el funcionamiento de la red, debe enunciarse que esta depende del creador, por ejemplo, en el supuesto de la terminación unilateral de los contratos por el productor, la red inmediatamente debe dejar de existir, máxime cuando por dejar de participar en la misma, no hay nadie que pueda reemplazar al creador en las obligaciones que le asisten y le son propias a razón de la naturaleza contractual. Una clara referencia a lo anterior es la enseñanza en los procesos que imparte el creador de la cadena cuando el contrato le genera este tipo de obligaciones.

En general, el empresario por economía y modernidad en la contratación, crea un sistema de acuerdo con las condiciones del mercado al cual quiere adentrarse con planes a largo plazo, contratando con otros empresarios, sean sociedades o no, para que colaboren de manera integrada en la comercialización del producto. En unos eventos la colaboración va hasta la conclusión del negocio y en otros, hasta la venta de los productos; estas prestaciones benefician el goodwill perteneciente a la marca de los productos.

La red también refuerza la forma de los contratos de colaboración, tales como el de 
distribución, concesión y franquicia, en el sentido que todos son contratos marco o de adhesión que incorporan condiciones generales de contratación y que por lo general se plasman en un documento privado. Esta estructura tiene varias características:

1. La red la demarca el fabricante o productor, franquiciante o concedente de ser el caso, y de ahí se deriva si es integrada de forma vertical (productores/mayoristas/minoristas) u horizontal (entre productores).

2. La red, dependiendo de los canales que se utilicen, es en mayor o menor medida, más integrada o no. Este cierre no implica subordinación derivada de los contratos que la conforman ni jurídica ni económicamente.

3. Es de carácter mercantil, en vista de que los actos o negocios que redundan para su consecución conllevan ánimo de lucro, entendiéndolo como presupuesto del numeral 12 del artículo 20 del Código de Comercio como empresas de fabricación y de circulación de bienes.

4. Puede ser directa cuando el fabricante utiliza su misma organización empresarial para la puesta de colocación final al consumidor, e indirecta cuando emplea los canales para que por intermedio de estos lleguen los productos al mercado deseado.

5. No acarrea por existir, la creación de una persona jurídica, aunque sí la creación de una organización en virtud de los contratos celebrados.

Sin un entendimiento diáfano de qué es la red de distribución no se podrá colocar el contrato objeto de análisis en el esquema exacto, de tal suerte que si se llega a comprender la función que ejerce la franquicia como canal dentro de una red, su conceptualización será más clara.

\section{La red de franquicias.}

La red de franquicias es un derivado del género llamado red de distribución, que explica todo un cúmulo de redes compuestas por contratos de franquicias, denominados comúnmente como business format franchise.

La red de franquicias participa de la comercialización como un mecanismo para cumplir varios propósitos, tales como la facilidad para la circulación del producto o servicio; la comunicación de la publicidad a sus canales; la identificación del máster franquiciante así como del franquiciante en aras de señalar la responsabilidad jurídica; mostrar, en principio, quién debe prestar la preparación de los franquiciados a través de la etapa de formación y entre otras, la de determinar la integración de la cadena entre el franquiciante y los franquiciados.

De no contar con los diferentes canales que participan de la red, el franquiciante no tendría otra forma de inversión económica y tampoco encontraría la seguridad jurídica de mantener los valores de los intangibles que su éxito ha generado. Cierto es que si la red deja de manifestar el control o la integración necesaria en cuanto a la franquicia, suscitaría un eventual peligro de un desmedro al goodwill marcario y empresarial del franquiciante.

Se resalta que a diferencia de las redes conformadas por otros canales de comercialización, una particularidad de la red de franquicias es su nivel de integración fungiendo como un elemento de esencia contractual. A pesar de que el contrato referido sea atípico y no estén del todo claros sus elementos, se puede entender que mientras la red sea más integrada es porque hay correlativamente una representación del control.

De este modo se precisa que el control debe entenderse como un aspecto esencial para la existencia del contrato de franquicia (Código 
Civil, art. 1501; Código de Comercio, art. 898), y como consecuencia de ello, exige la necesaria aparición de una red integrada que responde a ese control natural, so pena de una inexistencia jurídica.

La red es necesaria de comprender a la hora de justificar las funciones de las formalidades ad luciditatem y ad regularitatem, ya que sus características explican cómo un productor tiene obligaciones que a la postre derivarían en responsabilidades por su no cumplimiento. De no existir una red integrada, no podría haber un control por carecer su representación, y por lo mismo, tampoco podría haber una franquicia efectiva y pública, a menos que el franquiciante cumpla con ciertas formalidades como se verá más adelante.

\section{Las formalidades ad luciditatem y ad regularitatem en el contrato de franquicia}

\section{La forma y las formalidades en el contrato.}

La forma en el contrato tiene que ver con el reconocimiento del mismo ante el ordenamiento jurídico para ser contemplado o perceptible y llevar así los efectos que la ley prescribe para los actos creados por las partes. En palabras de Scognamiglio (1991) "la declaración es la forma más difundida por ser la que corresponde mejor a la necesidad práctica más intensa: la de hacer conocible el contenido del acto a los otros interesados" (p. 154); y según Paladini (2011) "la forma es el instrumento por medio del cual las partes manifiestan su consentimiento negocial. Las funciones más significativas que la forma puede asumir en el ámbito negocial son la de $a d$ substantiam y la de ad probationem" (p. 97).

En efecto, las anteriores formalidades son de indudable valía en el ámbito jurídico colombiano, tanto para la validez como para la prueba del contrato y de cualquier negocio jurídico. La máxima latina solus consensus obligat también propuesta en nuestro Código Civil en el artículo 1500 describe el principio de libertad de forma, el cual es dominante, por regla general, tanto en el derecho civil como para nuestro ordenamiento jurídico mercantil y a él nos sometemos para la manifestación de voluntad, su reconocibilidad y por supuesto de cara a la creación del iter contractual.

Para Rocco (citado por Arrubla, 2012, p. 36) la libertad de forma se beneficia del progreso cultural y las relaciones económicas, lo que sin duda repercute en el tráfico jurídico. El legislador en su afán de proteger a los contratantes cuando les impone alguna formalidad (ciertas publicidades en los actos, o la inscripción o registro so pena de sanción), limita la forma transformándola en una figura jurídica distinta que abarca varias funciones.

De esta suerte la restricción a este principio puede dar como resultado específicas formalidades según las cuales tendrá incidencia en la existencia (ad solemnitatem), en la validez (ad validitatem), en la prueba (ad probationem), en la oponibilidad y efectividad del contrato (ad regularitatem) o cuando se protege a la parte débil en un contrato (ad luciditatem) desembocando en multas como sanción a su inobservancia o bien en la invalidez del negocio.

Pero todo lo precedente no es más que la declaración de las limitaciones al principio de libertad de formas, dadas ya sea por la voluntad de las partes o impuestas por el ordenamiento jurídico, en efecto, como ejemplo de ello se observa el artículo 824 de nuestro estatuto mercantil en donde impera la libertad de forma y por excepción, nos muestra la solemnidad para la formación del negocio jurídico.

La formalidad entonces es la libertad de forma en sentido restringido, tal como lo entiende Bianca (2007): "la consagración normativa de cargas formales constituye una derogación al principio de la libertad de forma" (p. 296). Habría que decir también, que algunas opinio- 
nes están dirigidas a contrariar lo ya dicho, en cuanto a que el ordenamiento determina la libertad como la generalidad, pero mientras más se profundiza en ello, al parecer, más se apunta a que la formalidad no es la excepción. En este sentido Valencia (citado por Arrubla, 2012) manifiesta que "nuestra legislación presenta una regresión al formalismo, y la solemnidad del acto pasa a ser el género mientras la consensualidad queda como especie" (p. 37).

Existe, sin embargo, una relación estrecha entre forma y formalidad, pero a lo que se atiende en este documento es a las funciones y los efectos que las formalidades desarrollan, de tal modo que su posición en nuestro ordenamiento jurídico como normas de orden público, y la importancia que representan en el ámbito de los contratos, son fundamentales.

\section{Las formalidades como normas de orden público.}

Podemos observar cómo funcionan las formalidades en nuestro sistema privado, de tal manera que hay voces que recogen la regla de que aquellas tienen el carácter de orden público. Larrain (1994, p. 337) expresa que las partes no pueden eliminar las solemnidades convirtiendo un acto solemne en uno consensual, pues estas se estiman son de orden público. El magistrado Edgardo Villamil expresa con ocasión a la solemnidad marcada en las capitulaciones matrimoniales lo siguiente:

Una segunda consideración emerge de la exigencia de solemnidad y de la intervención del notario. Consiste en que este debe velar por la conformidad del acto con las reglas de orden público y las buenas costumbres, de modo que hará las admoniciones necesarias como manda, a título de ejemplo, el artículo 1780 del Código Civil. Y el hecho de que las capitulaciones deban observar las reglas de solemnidad de los actos y las "buenas costumbres" (artículo 1773 ibídem), pregna de orden público la institución, a la luz del artículo 16 ibídem, según el cual "no podrán derogarse por convenios particula- res las leyes en cuya observancia están interesados el orden y las buenas costumbres" (Sentencia del 29 de Julio de 2011).

La Superintendencia de Sociedades (2008) nos ofrece un concepto de normas imperativas o de orden público que ayudan a dilucidar, en materia mercantil, cómo debemos entenderlas:

Normas imperativas: son aquellas que en su misma esencia son obligatorias, no solo se inspiran en los principios generales derivados de la noción de orden público, la seguridad del Estado, las buenas costumbres, sino que tienden a moralizar y a proteger la profesión del comercio. Las que determinan las condiciones de validez de los contratos, imponen obligaciones a los profesionales del comercio, exigen solemnidades para la celebración de ciertos actos o las que imponen sanciones por el incumplimiento de exigencias o requisitos legales (p. 01).

En este sentido, las normas que imponen formalidades son imperativas por atender principios generales del orden público $\mathrm{y}$, además, comprenden varias funciones como la de protección a la profesión del comercio, imponer obligaciones al comerciante, etc. La necesidad de hacer visible la red de franquicia, así como la razón de hacer pública la condición de ser un controlador en un sistema de distribución, responde directamente a la manifestación de seguridad que las normas de orden público defienden. Si bien redundaría en el franquiciado como sujeto débil en la relación contractual, también incidiría en los consumidores, usuarios finales del producto o servicio de comercialización.

Como ya se dijo, el artículo 16 del Código Civil no permite que las partes deroguen por acuerdo las disposiciones de orden público, luego entonces tampoco se puede colegir que las formalidades que a continuación se analizan, una vez demostrada su necesidad, sean excusables para la parte contractual que crea la red de franquicia. 


\section{La importancia de las formalidades ad luciditatem y ad regularitatem en el contrato de franquicia. Una obli- gación del franquiciante.}

Hoy en día se está desarrollando una nueva corriente denominada neoformalismo negocial que se caracteriza "por la introducción de numerosas hipótesis de requisitos de forma en función de la protección del llamado contratante débil" (Paladini, 2011, p. 112). Según lo expuesto, nos encontramos para el caso de la franquicia con dos formalidades de este tipo, una que apunta a proteger al consumidor específicamente como lo es la formalidad ad luciditatem, y otra que es la formalidad ad regularitatem que va encaminada a que se surta la publicidad y a proteger la utilidad de las obligaciones del contrato entre las partes, es decir, a blindar la efectividad del contrato.

En cuanto a la formalidad ad luciditatem esta suele relacionarse con el consumidor, en su claro beneficio. Garrote (citado por Gómez, 2010) opina que la formalidad ad luciditatem es la que llena "requisitos especiales de forma en el contrato con el objeto de proteger a los consumidores" (p. 158).

Adviértase que este tipo de formalidad podría observarse en ámbitos que presentan una asimetría contractual, tal como la que normalmente sucede entre el empresario y el consumidor, sin circunscribir la formalidad a una sanción en particular en caso de su inobservancia. Dentro de este contexto su característica es que responde a varias circunstancias para la protección a la parte débil. En este sentido Gómez (2010) comenta:

En ciertos ámbitos el control se caracteriza por una asimetría de poder contractual: una parte tiene más poder contractual que la otra. Para contrarrestar esa asimetría, el ordenamiento instaura una serie de mecanismos de protección de la parte débil: entes de control, ligas de consumidores, derecho de información, garantía mínima, procedimientos ad- ministrativos y jurisdiccionales expeditos (D $3466 / 82$ ). Con esa misma finalidad, el ordenamiento establece una serie de formalidades $a d$ luciditatem [...] (p. 158).

La formalidad ad luciditatem no tiene un régimen específico que entable unas consecuencias jurídicas definidas, pues estas varían según el caso, por ejemplo, en la misma ley 1480 de 2011 vemos que por la omisión de la formalidad en materia de garantía suplementaria recaemos en una inexistencia, según el artículo 14, y para las operaciones en sistemas de financiación o para la prestación de servicios que supone la entrega de un bien, la omisión de la formalidad genera una sanción patrimonial de acuerdo con el artículo 61 de la ley 1480 de 2011.

Ciertamente la relación franquiciante/ franquiciado implica que el consumidor en su intervención se convierte en la parte débil de toda la cadena de comercialización, y como respuesta a esta situación se implementan varios mecanismos que contrarresten ese escenario. De manera general a esto se le conoce como formalidad ad luciditatem.

Adviértase que la función de publicidad del control envuelve otro tipo de formalidad que entra en juego, la llamada ad regularitatem. Esta formalidad cumple con dos funciones: a) la de dar oponibilidad al acto cumpliendo con la publicidad debida en el registro, la cual ayuda al consumidor a saber la situación de control del franquiciado y b) la de otorgar efectividad al contrato celebrado entre franquiciante y franquiciado al dar utilidad a sus obligaciones.

Se aclara que la formalidad ad regularitatem se genera en virtud de la ley o la voluntad de las partes al someter a inscripción el acto ante la autoridad competente, en tanto busca su efectividad, para la cual, las obligaciones comenzarán su verdadero ejercicio a partir del referido registro o cumplimiento de la forma. Puig, Gete-Alonso, Calera, Rodríguez y Hualde (2004) sostienen: 
[...] los contratantes pueden exigirse privadamente el ejercicio de las obligaciones dimanadas del contrato, pero cuando intenten el ejercicio de las mismas ante una autoridad judicial, o ante terceros, o para lograr la inscripción en un Registro Público de los mismos, cada parte podrá compeler a la otra a que rellene (cumpla) con la forma exigida (p. 562).

La formalidad ad regularitatem la impone el legislador colombiano como un documento privado sujeto a inscripción ante la cámara de comercio que de incumplirse, no solo genera multas, sino que también inutiliza la efectividad del contrato en el sentido de que el franquiciado controlado solo podrá contar con el contrato, como prueba, para alegar ciertas responsabilidades.

Se puede afirmar que la subordinación como medida establecida en las disposiciones de la ley 222 de 1995 para el grupo empresarial es perfectamente aplicable al contrato de franquicia. Determinada la estrecha conexión entre el control contractual y el control natural manifestado en la red de franquicia a través de su integración, no cabe sino decir, que la ley prescribe una formalidad ad regularitatem y ad luciditatem a cargo de los franquiciantes en Colombia, la cual consiste en la inscripción del documento privado que contemple la situación de subordinación en el registro mercantil, so pena de multas a más tardar treinta días siguientes a la configuración de tal situación (artículo 30, ley 222 de 1995).

Las formalidades que giran alrededor del control contractual apuntan a proteger a la parte débil en la contratación o en la relación de consumo si es del caso. Sin duda se presentan como parte débil del contrato de franquicia el consumidor y el franquiciado por estar sujetos a un contrato de adhesión con condiciones generales. Piénsese el caso de no seguir la formalidad en relación con el franquiciado, las consecuencias negativas son que no se podría cumplir de f0rma eficiente lo que dictan los artículos 7, 10, 13, 17, 23, 24, 38,39 y 40 de la ley 1480 de 2011 , ya que estos imponen obligaciones al franquiciante que al desconocerlas no hace efectivo el contrato.

En cuanto al consumidor, parte débil dentro del esquema de una red de franquicia, el incumplimiento de las formalidades produce la consecuencia negativa de hacer inoponible al consumidor que al franquiciado lo controlan, y a un mismo tiempo causa el desconocimiento de la relación de consumo de la que forma parte, no haciéndole conocible el derecho a reclamar directamente al productor; tal es el caso del deber de información en los productos defectuosos (artículo 19, ley 1480 de 2011).

En suma, la importancia de las formalidades ad luciditatem y ad regularitatem radica en las funciones jurídicas que cumplen en beneficio del franquiciado y del consumidor.

\section{Conclusiones}

Cuando el franquiciante influye marcadamente en la gestión administrativa del franquiciado causa el llamado control contractual (ley 222 de 1995, art. 27 num. 3). A su vez, la creación de una red de franquicia implica la necesaria integración, un método de comercialización impuesto y otras políticas que son menester dentro de una red de franquicia.

Al manifestarse un control natural desde el negocio jurídico representado en una red, el franquiciante debe cumplir con formalidades que desde la teoría presentan una protección a la parte débil de la contratación como a los consumidores. Las formalidades se manifiestan en el artículo 30 de la ley 222 de 1995, como quiera que regula el tema de la inscripción del documento privado que recoge la situación de control. A este respecto las formalidades ad luciditatem y ad regularitatem encierran funciones que apuntan a proteger al consumidor y a la efectividad del contrato en relación con el franquiciado. 
Una vez hechas las precisiones sobre la importancia de las formalidades, se concluye que la inscripción en el registro público de la situación de control se vincula de modo imperativo con las funciones que cumplen las formalidades ad luciditatem y ad regularitatem. Partiendo de lo planteado anteriormente, todo conlleva que se convierta en obligación, para el franquiciante, adoptar la inscripción del control en cámara de comercio a propósito de la formación de la franquicia. La obligación se justifica en la función de las formalidades como norma de orden público, so pena de incurrir en multas o causar un claro perjuicio a los consumidores y al franquiciado.

\section{Nota}

1 La información sobre la costumbre certificada en materia de Franquicia se encuentra en el siguiente enlace: http://www.ccb.org.co/ Investigaciones-Bogota-y-Region/CostumbreMercantil/Listado-de-Costumbres-Mercantiles

\section{Referencias}

Arrubla, J. A. (2012). Contratos mercantiles, Teoría general del negocio mercantil $\left(13^{\mathrm{a}}\right.$ ed.) Colombia: Legis.

Asamblea General de las Naciones Unidas. (2007). Informe del Grupo de Trabajo $\mathrm{V}$ (Régimen de la Insolvencia) sobre la labor de su $31^{\circ}$ Período de Sesiones. Viena: Comisión de las Naciones Unidas para el Derecho Mercantil Internacional. Recuperado de https://documents-dds-ny. un.org/doc/UNDOC/GEN/V07/800/92/ PDF/V0780092.pdf?OpenElement

Bianca, C. M. (2007). Derecho civil. 3. El contrato. Bogotá: Universidad Externado de Colombia.

Bliman, J. D. (2006). El Contrato de Franquicia Comercial. En M. Velandia (Coord.), El Tlc y el derecho de la Distribución
Comercial (pp. 172-182). Medellín: Biblioteca Jurídica Dike.

Camacho, M. E. (2005). Régimen Jurídico aplicable a los contratos atípicos en la Jurisprudencia Colombiana.Revist@EMercatoria, 4(1). Recuperado De http:// revistas.uexternado.edu.co/index.php/ emerca/article/view/2106/1883

Constitución Política (1991). Congreso de la República de Colombia. Colombia.

Decreto 410 de 1971. Por el cual se expide el Código de Comercio. Diario Oficial No. 33.339. Presidencia de la República, marzo de 1971.

Decreto 3466 de 1982. Por el cual se dictan normas relativas a la idoneidad, la calidad, las garantías, las marcas, las leyendas, las propagandas y la fijación pública de precios de bienes y servicios, la responsabilidad de sus productores, expendedores y proveedores, y se dictan otras disposiciones. Presidencia de la República, diciembre de 1982.

Echebarría, J. A. (1995). El contrato de Franquicia. Madrid: Editorial McGrawHill.

Farina, J. M. (2005). Contratos Comerciales Modernos (3ra ed.). Buenos Aires: Editorial Astrea.

Fontcuberta, J. (2009). El contrato de distribución de bienes de consumo y la llamada indemnización por clientela. Madrid: Editorial Marcial Pons.

Gómez, C. (2010). Teoría del Contrato. Medellín: Editorial Universidad de Medellín.

Izuzquiza, M. L. (2008). El contrato de Franquicia. Cartapacio de Derecho, 14, Recuperado de http://www.cartapacio.edu.ar/ ojs/index.php/ctp/article/view/1090/1001 
Larrain, H. (1994). Lecciones de Derecho civil. Chile: Editorial jurídica de Chile.

Ley 57 de 1887. Con arreglo al artículo 52 de la Constitución de la República, declárase incorporado en el Código Civil el Título III (arts. 19-52) de la misma Constitución. Diario Oficial No. 7.019. Congreso de la República de Colombia, abril de 1887.

Ley 222 de 1995. Por la cual se modifica el Libro II del Código de Comercio, se expide un nuevo régimen de procesos concursales y se dictan otras disposiciones. Diario Oficial No. 42.156. Congreso de la República de Colombia, diciembre de 1995. Recuperado de http://www. secretariasenado.gov.co/senado/basedoc/ ley_0222_1995.html

Ley 1480 de 2011. Por medio de la cual se expide el Estatuto del Consumidor y se dictan otras disposiciones. Diario Oficial No. 48.220. Congreso de la República de Colombia, octubre de 2011. Recuperado de http://www.secretariasenado.gov.co/ senado/basedoc/ley_1480_2011.html

Martorell, E. E. (1993). Tratado de los Contratos de Empresa. Buenos Aires: Editorial Depalma.

Marzorati, O. J. (2008). Sistemas de Distribución Comercial (3ra ed.). Buenos Aires: Editorial Astrea.

Navas, M., \& Mosquera, A. M. (2009). El contrato de Franquicia: Aportes y tendencias en el derecho comparado sobre la responsabilidad del franquiciado. Vniversitas, 119, 279-304. Recuperado de http://www.scielo.org.co/pdf/vniv/n119/ n119a17.pdf

Oficio 220-058496 del 10 de diciembre de 2007. Asunto: Representación Judicial de las Personas Jurídicas - Curador Ad- litem. Superintendencia de Sociedades, diciembre de 2007.

Oficio 220-016647 del 25 de enero de 2008. Asunto Normas que regulan el Contrato de Arrendamiento Comercial Superintendencia de Sociedades, enero de 2008.

Paladini, M. (2011). La forma del contrato. En A. Echeverri (Dir.), Responsabilidad civil y negocio jurídico (pp. 97-118). Bogotá: Editorial Ibañez.

Peres, M. (2003). Franquicias: Derecho Uniforme y Tecnologías de Información. En A. Zapata de Arbeláez, Derecho Internacional de los Negocios (pp. 209. 228). Bogotá: Universidad Externado De Colombia.

Puig, L., Gete-Alonso, X., Calera, M., Rodríguez, J., \& Hualde, J. (2004). Manual de Derecho Civil. Madrid: Marcial Pons.

Ramírez, L. (2001). El Control y los Grupos de Sociedades. Anuario da Facultade de Dereito da Universidade da Coruña, 5, 629-663. Recuperado de http://ruc.udc. es/dspace/bitstream/handle/2183/2140/

AD-5-27.pdf? sequence $=1 \&$ isAllowed $=\mathrm{y}$

Reyes-Villamizar, F. (2006). Derecho Societario (Tomo 2, 2da ed.). Bogotá, Colombia: Editorial Temis S.A.

Scognamiglio, R. (1991). Teoría general del contrato. Bogotá: Universidad Externado de Colombia.

Sentencia C-1141 (2000, agosto 30). Acción de inconstitucionalidad. M. P. Eduardo Cifuentes Muñoz. Corte Constitucional. Recuperado de http://www.corteconstitucional.gov.co/relatoria/2000/C-1141-00.htm

Sentencia del 30 de Abril de 2009. Expediente No. 258993193992199900629 01. M. 
P. Pedro Octavio Munar Cadena. Corte Suprema de Justicia. Sala de Casacion civil.

Sentencia del 29 de Julio de 2011. Expediente No. 2007-00152-01. M. P. Edgardo Villamil Portilla. Corte Suprema de Justicia. Sala de Casación civil.

Sentencia del 16 de Octubre de 2014. Expediente No. 05001-23-31-000-2005-06757-0 La Sala decide el recurso de apelación interpuesto por la demandada contra la sentencia del 7 de junio de 2012, proferida por el Tribunal Administrativo de San Andrés, Providencia y Santa Catalina
1 (19939). Consejo de Estado Sala de lo Contencioso Administrativo, BogotáColombia.

Simón, H. (2007). Contratos Modernos de Distribución Comercial. Buenos Aires: Lexisnexis Argentina S.A.

Unión Europea. Reglamento de la Comunidad Económica Europea 4087 de 1988. relativo a la aplicación del apartado 3 del artículo 85 del Tratado a categorías de acuerdos de franquicia. Diario Oficial No. L 359. Comisión de la Comunidad Económica Europea, noviembre de 1988. 
